\title{
Erratum to: Interaction of Paroxetine with Mitochondrial Proteins Mediates Neuroprotection
}

\author{
Joseph P. Steiner ${ }^{1,2} \cdot$ Muznabanu Bachani ${ }^{2} \cdot$ Brett Wolfson-Stofko $^{1} \cdot$ \\ Myoung-Hwa Lee ${ }^{3}$ - Tongguang Wang ${ }^{2}$ - Guanhan $\mathrm{Li}^{3} \cdot$ Wenxue $\mathrm{Li}^{3}$ - David Strayer ${ }^{4}$. \\ Norman J. Haughey ${ }^{1}$ Avindra Nath ${ }^{1,2,3}$
}

Published online: 21 December 2015

(C) The American Society for Experimental NeuroTherapeutics, Inc. 2015

Erratum to: Neurotherapeutics (2015) 12:200-216

DOI 10.1007/s13311-014-0315-9

Tongguang Wang appeared incorrectly on the original publication of this article. The author list is corrected here.

The online version of the original article can be found at http://dx.doi.org/ 10.1007/s13311-014-0315-9.

\section{Joseph P. Steiner}

steinerjp@ninds.nih.gov

$\triangle$ Avindra Nath

natha@ninds.nih.gov

1 Department of Neurology, Johns Hopkins University School of Medicine, Baltimore, MD 21287, USA

2 Translational Neuroscience Center, National Institute of Neurological Diseases and Stroke, National Bldg 10, Room 7C-105, 10 Center Drive, Bethesda, MD 20892, USA

3 Section of Infections of the Nervous System, National Institute of Neurological Diseases and Stroke, National Institute of Health, Bldg 10, Room 7C103, 10 Center Drive, Bethesda, MD 20892, USA

4 Department of Pathology, Anatomy and Cell Biology, Thomas Jefferson University, Philadelphia, PA 19107, USA 